\title{
DIREITO AMBIENTAL DO TRABALHO: REFLEXO DA CONTEMPORANEIDADE ${ }^{(*)}$
}

ENVIRONMENTAL LABOUR LAW: A CONTEMPORARY REFLECT

Julio Cesar de Sá da Rocha ${ }^{(* *)}$

\section{RESUMO}

Sustenta-se a tese do surgimento da disciplina Direito Ambiental do Trabalho, que representa um novo paradigma em matéria de proteção juridica à saúde do trabalhador. Nesse sentido, percebe-se o aparecimento in statu nascendi de um sistema normativo e científico acerca do meio ambiente do trabalho, baseado na prevenção do dano e na promoção de locais de trabalho saudáveis.

\section{Palavras-chave}

Direito ambiental do trabalho e Saúde dos trabalhadores.

\section{ABSTRACT}

We support the emergence of a specific subject: Working Environmental Law that represents a new paradigm about the juridical protection of worker's health. We can see an emerging of a normative and scientific system which is based in a preventive approach that promotes healthy workplaces.

\section{Keywords}

Working environmental law and Worker's health.

(*) Pesquisa realizada com apoio institucional da CAPES - Brasília, mediante concessão de Bolsa de Estágio no Exterior (PDEE).

("*) Doutor em Direito pela PUC, São Paulo. Professor da Universidade Estadual de Feira de Santana. Pesquisador do CNPq. Assessor de Juiz do Tribunal Regional do Trabalho da 5a Região. 


\section{EMERGÊNCIA DO DIREITO AMBIENTAL DO TRABALHO}

A emergência e o desaparecimento de uma disciplina legal significa que algo de fundamental se está transformando na sociedade. Com efeito, o surgimento de um novo paradigma indica a possibilidade de caminhos e abordagens diferenciados de tutela jurídica. Como resultado, a antiga ordem e seus significados tendem a ser gradualmente substituídos.

Em vista disso, surge um sistema normativo do meio ambiente do trabalho como uma racionalidade baseada na prevenção ao dano e na precaução. De imediato, observa-se o desenvolvimento de legislações que tratam do tema em diversos campos jurídicos estatais: Dinamarca, Finlândia, Noruega, Suécia, Holanda, Brasil, Espanha etc.; em organizações internacionais: OIT, Convenção 148 e 155; em documentos internacionais: PNUMA, Agenda 21 e Pacto Internacional sobre Direitos Econômicos, Sociais e Culturais; convenções internacionais: Convenção Nórdica em Meio Ambiente do Trabalho.

Além disso, encontram-se disposições sobre o meio ambiente do trabalho em documentos fundacionais e diretivas dos blocos regionais União Européia, art. 137 (ex art. 118), Tratado de Roma/Comunidade Européia e Diretiva 89/391/CEE. Enfim, corrobora-se, irrefutavelmente, a argumentação da emergência de uma proteção jurídica específica e diferenciada.

A par disso, o tema do meio ambiente do trabalho tem começado a receber tratamento doutrinário no campo do Direito $\left.A m b i e n t a\right|^{(1)}$ e do Direito do Trabalho(2). Por exemplo, o jurista francês Michel Prieur, em seu Droit de l'environment( ${ }^{(3)}$, destina inteiro capítulo ao meio ambiente do trabalho, reco-

(1) Cf. Daniela Câmara FERREIRA \& Guilherme José Purvin de FIGUEIREDO. Direito constitucional ao meio ambiente do trabalho seguro e saudável, pp. 103-115. Guilherme José Purvin de FIGUEIREDO. Direito ambiental e a saúde dos trabalhadores. Celso A. P. FIORILLO \& Marcelo Abelha RODRIGUES. Manual de direito ambiental e legislação aplicável, pp. 68-71. Paulo Affonso Leme MACHADO. Direito ambiental brasileiro, pp. 407-408. Julio Cesar de Sá da ROCHA. Direito ambiental e meio ambiente do trabalho: dano, prevenção e proteção jurídica. Idem. "Direito ambiental e meio ambiente do trabalho: considerações sobre o ambiente de trabalho rural e a questão dos agrotóxicos", pp. 153-183. Idem. "Meio ambiente do trabalho", pp. 26-34. Sobre uma atuação mais geral em torno dos direitos difusos e coletivos e em matéria processual: José Luiz Dias CAMPOS. O Ministério Público e o meio ambiente do trabalho: responsabilidade civil e criminal do empregador e prepostos. Celso A. Pacheco FIORILLO. Os sindicatos e a defesa dos interesses difusos no processo civil brasileiro. Nelson NERY JUNIOR \& Rosa M. B. de Andrade NERY. Código de processo civil comentado e legislação extravagante em vigor. Jorge Luiz USSIER. A defesa do meio ambiente do trabalho e da saúde do trabalhador pelo Ministério Público Estadual, pp. 44-52.

(2) Cf. Mário BONCIANI (org.). Saude, ambiente e contrato coletivo de trabalho. Ives Gandra MARTINS FILHO. A defesa dos interesses coletivos pelo Ministério Público, pp. 1430-1434. Raimundo Simão MELO. Segurança e meio ambiente do trabalho: uma questão de saúde pública, pp. 158-164. OIT. Introducción a las condiciones y el medio ambiente de trabajo. João José SADY. Direito do meio ambiente do trabalho. João Hilário VALENTIM. Direito do trabalho e meio ambiente, pp. 1453-1459.

(3) Michel PRIEUR. Droit de l'environment, quatrième partie, chapitre 5 - L'environnement du travail. 
nhecendo, de logo, a importância da problemática da poluição nos locais de trabalho.

Por seu turno, o nórdico Hákan Hydén, na obra coletiva The Nordic Labour relations model: labour law and trade unions in the Nordic countries, today and tomorrow(4), escreve longo capítulo sobre o meio ambiente do trabalho em face das relações de trabalho.

O certo é que existe uma bordeline, dito de outra forma, um espaço em comum, uma área ainda não completamente definida, ocupada pela tutela jurídica e estudo doutrinário sobre o meio ambiente do trabalho.

Cabe aqui salientar a ausência de uma abordagem integrada do Direito Ambiental e Direito do Trabalho, que, isoladamente, não conseguem compreender a dimensão integral do meio ambiente do trabalho.

De certo modo, essas disciplinas possuem postulados e princípios bastante peculiares, que revelam pressupostos e ideários em determinado tempo-espaço (dimensão) de produção jurídica. O Direito do Trabalho objetiva primordialmente a regulação das relações laborais e a proteção do ser humano trabalhador; o Direito Ambiental, a proteção do meio ambiente e a proteção do ser humano tomado na sua generalidade.

Por conseguinte, o Direito Ambiental dificilmente penetra no Direito do Trabalho, e vice-versa, na medida em que uma disciplina não é absorvida pela outra, já que possuem racionalidades e princípios bastante específicos, resultado de uma circunstância social e histórica determinada.

No entanto, a percepção da existência de liame entre as disciplinas, através do objeto comum - meio ambiente do trabalho - e o surgimento de legislações e obras doutrinárias sobre a matéria revelam a necessidade de sistematização teórica acerca do tema. Como resultado, possibilita-se que as disciplinas matrizes conservem suas características e peculiaridades, mas forneçam elementos basilares para entendimento de uma nova abordagem jurídica: o Direito Ambiental do Trabalho.

É necessário afirmar que não se constitui disciplina pronta, delineada, estabelecida em todos os seus contornos; caracteriza-se como instrumento de análise da tutela jurídica ao meio ambiente do trabalho; seu desenvolvimento teórico exige a obra e sensibilidade de juristas e pesquisadores.

Nesse sentido, o Direito Ambiental do Trabalho é compreendido como sistema normativo que tutela o meio ambiente do trabalho (de forma imediata) e a saúde dos trabalhadores (de forma indireta), e como disciplina jurídica in statu nascendi que descreve e compreende essa proteção normativa, tendo em vista o trabalhador em seu entorno de trabalho.

(4) Hákan HYDÉN. "Working environment", chapter IV - Working environment, p. 133. 
Convém registrar que essa disciplina se propõe a estabelecer análise sobre a proteção jurídica ao meio ambiente do trabalho, absorvendo, principalmente, elementos do Direito do Trabalho (proteção à incolumidade do trabalhador) e do Direito Ambiental (proteção ao meio ambiente), sem descurar das influências de outras disciplinas, como o recente Direito da Saúde(5).

Como foi observado, existe rompimento com a proteção tradicional, estabelecendo-se métodos coletivos de tutela e adoção de medidas relacionadas com a prevenção. Ademais, não se deixa de compreender a relação contratual existente entre trabalhador e empresário, mas aponta-se, prioritariamente, o direito pleno à integridade psíquica e física do operário-contraente, determinando-se relevância da dimensão integral dos ambientes de trabalho.

O certo é que o Direito Ambiental do Trabalho se caracteriza como instrumental de análise, em face ao aparecimento de considerável material normativo subre o tema do meio ambiente do trabalho.

Em vista disso, pode existir a abertura de diálogo em outros quadrantes e sob outras justificativas teóricas, compreendendo, sistematicamente, o momento do direito na atualidade e seu impacto sobre a sociedade.

\section{DIREITO AMBIENTAL DO TRABALHO: NATUREZA JURÍDICA}

Diante das discussões a respeito do Direito Ambiental do Trabalho, torna-se oportuna a análise da localização dessa disciplina (sua natureza jurídica) nos ramos do direito. Nesse sentido, a disciplina surge como resultado de ruptura de tratamento centrada unicamente no binômio direito público e direito privado, na medida em que os bens juridicamente tutelados - saúde (do trabalhador) e meio ambiente (do trabalho) - correspondem a interesses ${ }^{(6)}$ que não são puramente estatais nem estritamente particulares.

(5) O Direito da Saúde, que pode ser entendido como o conjunto de normas jurídicas reguladoras da atividade do poder público destinado a ordenar a proteção, promoção e recuperação da saúde, e a organização e o funcionamento dos serviços correspondentes $\theta$ asseguradores deste direito. Cf. Julio Cesar de Sá da ROCHA. Direito da saúde: direito sanitário na perspectiva dos interesses difusos e coletivos, p. 49. Francesco D. BUSNELLI \& Umberto BRECCIA. II diritto alla salute, pp. 23-29. Os autores abordam o tema do direito à saúde, incorporando preocupação sobre a saúde no meio ambiente do trabalho, salientando a necessidade de tutela jurídica com imposição de medidas preventivas. Enfim, percebe-se que o Direito da Saúde oferece instrumental doutrinário necessário para a compreensão inclusive da dimensão da saúde como completo bem-estar físico, mental e social e não apenas como ausência da doença e outros agravos, elemento indispensável à efetivação da dignidade humana.

(6) Em vista disso, toma-se a noção de interesse juridico aquela aspiração que tem como referencial determinado conteúdo contido na norma que revela a relação da pessoa a um bem juridicamente tutelado. 
Necessário é que se afirme que a summa divisio entre direito público e privado tem recebido crítica contundente, na medida em que a linha divisória é por demais imprecisa e incapaz de representar a complexidade e diversidade das relações sociais contemporâneas, surgindo campos e demandas indeterminados, que não se limitam à clássica esfera estatal e privada.

Em verdade, a distinção entre direito público e privado remonta à Roma Antiga, sendo tradicional a idéia de que o direito público é aquele que tem relação com o Estado romano; e o direito privado, com aquele relativo aos interesses dos indivíduos. Não sem sentido proclamava Ulpiano no Digesto: jus publicum est quod statum rei romanae spectat, privatum quod ad singulorum utilitatem pertinet: sunt enim quoedam publice utilia, quoedam privatim.

Por seu turno, na atualidade, a distinção entre o panorama individual e estatal considera-se limitada, porque é cada vez mais constante a intervenção estatal no domínio privado, e ainda, o poder público pode agir resguardando interesses meramente estatais, sem preocupação com os interesses sociais (entendidos como aqueles desempenhados em relação à sociedade civil).

De resto, normas de caráter privado, e. g., normas de direito civil podem coexistir com disciplinas de ordem pública, como no campo do direito de família. Portanto, a fronteira entre público e privado torna-se cada vez mais sutil.

A par disso, a utilização da denominação de interesse público nem sempre oferece uma dimensão precisa da diversidade de situações que ocorrem entre interesses típicos da esfera pessoal e outros que são praticados pela esfera estatal.

Com efeito, surgem interesses sociais de coletividade, de comunidades de uma forma geral e de corpos intermediários (sindicatos, associações, corporações, multinacionais, partidos políticos), que não se enquadram necessariamente na categoria de interesse público. Ora, a noção de interesse público denota a presença estatal em primeiro plano, desaguando em uma aproximação necessária entre o interesse público e a entidade pública.

Ademais, a distinção entre público e privado pode permanecer. Entretanto, surge a necessidade de compreensão diferenciada que possa representar novas dimensões de tutela jurídica a interesses metaindividuais como terceiro termo, e não tão-somente centrada na estanque dicotomia tradicionalmente existente.

Desse modo, necessário é mencionar que, em virtude das suas características, difere de todo direito anterior, tanto público como privado, não 
sendo, portanto, nem público nem privado nem misto, mas uma terceira divisão do direito, que se deve colocar ao lado das outras conhecidas até agora $^{(7)}$.

O próprio Max Weber, depois de estabelecer o conceito de direito público e privado, aponta claramente que esta clássica distinção não apresenta critério legal e sociológico satisfatório( ${ }^{(8)}$.

Mais recentemente, nota-se a influência da doutrina italiana, principalmente dos estudos surgidos nos anos de 1970 com Cappelletti, Denti, Proto Pisani, Vigoriti, Trocker ${ }^{(9)}$, que tiveram seu ponto alto no Congresso de Pavia de $1974^{(10)}$. Com efeito, seus reflexos têm sido assimilados e refletidos em uma diversidade de legislações estatais ${ }^{(11)}$, corroborando-se a insuficiência da classificação do direito entre os paradigmas público e privado, por conta do momento atual e suas repercussões na sociedade de consumo.

Por conseguinte, pela própria existência dessa conflitualidade de massa, em que os danos não se restringem ao caráter individual, surgem, ou

(7) Como afirmaria Cesarino Júnior sobre a existência de um terceiro gênero no mundo jurídico, resgatando Georges Gurvitch. L'idée de droit social, Paris, 1932. CESARINO JÚNIOR. Direito social brasileiro, São Paulo: Freitas Bastos, 1953, pp. 120-121.

(8) Max WEBER. On law in economy and society, pp. 41-60. Julien FREUND. The sociology of Max Weber, pp. 250-251. Com efeito, para Max Weber, o direito público pode ser entendido como totalidade de normas que regulam as atividades estatais, aquelas que estabelecem instruções para os servidores públicos no que concerne às suas obrigações, e expressam hierárquica relação de comando e obediência, dominação e subordinação; e o de direito privado, como sendo normas que regulam condutas outras do que as estatais, e cobrem todas as matérias em cujas partes estão no mesmo nível jurídico.

(9) Com efeito, constitui de importância indiscutível o pensamento de Mauro CAPPELLETTI, e. g., "Appunti sulla tutela giurisdizionale di interesse colletivi o diffusi; Formações sociais e interesses coletivos diante da justiça civil". Além dele, outros autores italianos têm abordado o tema dos direitos difusos e coletivos, e. g., Guido ALPA \& Mario BESSONE. Elementi di Diritto Civile Vittorio DENTI. "Relazione introduttiva"; Massimo Severo GIANNINI. La tutela degli interessi colletivi nei procedimenti amministrativi. Andrea Proto PISANI. Appunti preliminari per uno studio sulla tutela giurisdizionale degli interessi collettivi (o piu esattamente: superindividuali) innanzi al giudice civile ordinario. Francesco D. BUSNELLI \& Umberto BRECCIA. II diritto alla salute.

(10) Cf. Ada Pellegrini GRINOVER. "A defesa do meio ambiente em juizo como conquista da cidadania", São Paulo: Revista de Direitos Difusos, vol. I, n. 2, A 60, 2000, pp. 121 e 128.

(11) A referência mais contundente é a do ordenamento jurídico brasileiro que, constitucionalmente, agasalha a proteção dos direitos difusos, conforme expressamente determina 0 art. 129, III, dentre uma multiplicidade de dispositivos sobre os "direitos de todos" (e. g., saúde, art. 194 e seguintes; educação, art. 208; cultura, art. 215; meio ambiente, art. 225). Além disso, no nivel infra-constitucional, existem importantes dispositivos no Código de Defesa do Consumidor (Lei n. 8.078/90, art. 81), na Lei de Ação Civil Pública (Lei n. 7.347/85, art. 1², IV), Lei de Ação Civil Pública para tutela de interesses metaindividuar concernentes aos deficientes físicos (Lei n. $7.853 / 89$, art. $3^{\circ}$ ) e por danos a investidores no mercado de valores mobiliários (Lei n. 7.913/89), Estatuto da Criança e Adolescente (Lei n. 8.069/90), dentre outros diplomas legais. Contudo, existe disciplina sobre esses direitos em outros paises, como em Portugal, que estabelece disciplina inclusive na esfera administrativa, como se percebe expressamente no Código do Procedimento Administrativo, quando se refere à legitimidade para iniciar procedimento administrativo para a proteção de interesses difusos (art. 53, II). 
melhor, reconhecem-se juridicamente determinados interesses denominados difusos e coletivos, como os impactos ao meio ambiente, à saúde, às relações de consumo. Com efeito, são direitos que envolvem grupos, classes, comunidades, revelando sua marca metaindividual na titularidade dos sujeitos coletivos e na indivisibilidade de seu objeto.

Desenvolvendo a noção, menciona-se que os direitos difusos são compreendidos como aqueles que perpassam a esfera individual, atingindo dimensões relativas a comunidades ou grupos indeterminados de pessoas, são afetos a situações que não exigem relação jurídica prévia entre seus portadores.

Por exemplo, isso se observa na descarga de resíduos tóxicos em uma região, contaminação de rede de água potável derivada de um manancial, poluição sonora em uma zona urbana, dentre outros. Associa-se a idéia do direito difuso à indeterminação dos sujeitos, à indivisibilidade de seu objeto e à ocorrência de circunstância fática que desencadeia proteção jurídica.

Deve ser destacado que os direitos coletivos são aqueles relativos a grupo, classe ou categoria determinada de pessoas, por isso, perfeitamente identificáveis; possuem uma dimensão eminentemente corporativa, pressupondo um "mínimo de coesão, de organização, de estrutura"(12).

Os direitos coletivos podem ser atingidos, por exemplo, quando acontece uma descarga de benzeno (elemento químico de alta insalubridade) em uma unidade produtiva no setor petroquímico, ou existe a necessidade de implantação de dispositivos protetivos (portas giratórias) em agências bancárias. Por exigência de cumprimento de acordo coletivo de trabalho, atingem-se direitos que têm como portadores categorias específicas e organizadas de trabalhadores.

O liame entre os direitos difusos e os direitos coletivos reside no seu caráter metaindividual, podendo ser agrupados, no mais das vezes, na denominação de direitos coletivos lato sensu; de outra maneira, os interesses difusos podem ter uma amplitude maior do que a órbita de uma coletividade organizada e definida, ressaltada pelo caráter corporativo; além disso, nos direitos difusos, considera-se o ser humano em sua dimensão genérica, agregado ocasionalmente pela ocorrência fática que determina sua tutela.

Por conseguinte, a classificação dos direitos difusos e coletivos resgata a concepção doutrinária esboçada por respeitados juristas e cientistas sociais de que o binômio público e privado não consegue representar todas as relações jurídicas existentes na contemporaneidade, principalmente aquelas originadas nas relações de massa e nos interesses refletidos nessas demandas.

(12) Rodolfo de Camargo MANCUSO. Interesses difusos: conceito e legitimação para agir. São Paulo: Revista dos Tribunais, 2000, p. 52. 
Em geral, quando se indagam questões de saúde do trabalhador e meio ambiente do trabalho, aparece em mente o interesse coletivo próprio de determinada categoria, diverso de um interesse social que corresponde a valores universalmente reconhecidos como fundamento da convivência de uma determinada sociedade.

No entanto, é prudente notar que, apesar de as máquinas, bens e instalações de uma empresa serem de titularidade privada, o meio ambiente de trabalho não pode ser compreendido dentro do regime geral de propriedade, na medida em que se caracteriza bem essencial à vida do trabalhador.

Claro que, na maioria das situações que envolvem o tema da saúde do trabalhador, se cogita, por exemplo, sobre o contingente de operários que exercem seu ofício em uma específica indústria e/ou a categoria que trabalha em determinado setor industrial. Contudo, o bem tutelado meio ambiente do trabalho não tem proprietário, seu equilíbrio e salubridade atinge todo e qualquer trabalhador.

De outra forma, situações que envolvam possibilidade de danos à saúde de indeterminado contingente de trabalhadores de variadas categorias podem se caracterizar como interesse difuso da coletividade, incalculável (massa indefinida), de operários que possam ser atingidos por determinada substância nociva, como, por exemplo, a contaminação orgânica pelo trabalho em ambiente que utiliza telhas de amianto (fabricada com substância cancerígena).

Todavia, novamente, o meio ambiente do trabalho integra a noção de meio ambiente como bem difuso. Decerto que o requisito dos efeitos de possiveis danos podem atingir uma determinada categoria (coletivo) ou uma massa indefinida de trabalhadores de diversas categorias (difuso). Entretanto, o meio ambiente do trabalho deve ser sempre tomado como um bem difuso a ser tutelado.

Em suma, o Direito Ambiental do Trabalho, quanto à sua natureza jurídica, nasce como disciplina que integra essa categoria de direitos; não se funda na titularidade de situação subjetiva meramente individual. Com efeito, não é supérfluo mencionar que não se ambiciona a realização de um interesse particular; ao contrário, reconhece-se que existe necessidade de uma proteção metaindividual (tutela coletiva lato sensu).

Nesse particular, legitimam-se não somente indivíduos que assumem titularidade para defesa de interesses altruísticos, diversos dos interesses relativos à própria personalidade, mas, prioritariamente, associações, sindicatos, centrais sindicais, órgãos governamentais que detêm condição de defesa desses direitos em caso de dano e ameaça de lesão.

Conseqüentemente, supera-se o tabu da necessidade de um interesse pessoal na prestação jurisdicional, na medida em que surgem interes- 
ses metaindividuais (coletivos lato sensu, superindividuais) que ensejam a proteção de toda e qualquer pessoa ${ }^{(13)}$. A amplitude de tutela à saúde e à saúde no meio ambiente do trabalho constitui manifestação que não pertence ao direito público, nem ao direito civil (privado), porquanto se refere à titularidade coletiva ${ }^{(14)}$.

Quando se está diante de interesses difusos e coletivos, via de regra, emerge uma solidariedade diferenciada e dificilmente encontrada no patamar de defesa dos interesses individuais. A proteção aos direitos difusos e coletivos configura-se como de tipo participativo, que pode ser exercida por todos aqueles que sejam seus portadores.

Com efeito, a proteção ao meio ambiente do trabalho carrega caracteres essencialmente difusos e coletivos. Em vista disso, quando se objetiva a melhoria de condições de um meio ambiente de trabalho, seu resultado atinge todos aqueles que trabalham naquele local.

A par disso, essa opção não invalida as hipóteses de compensação individual dos danos à saúde, na medida em que não se elimina a possibilidade de reparação individual pelos prejuízos porventura existentes.

Todavia, essa postura deve ser combinada prioritariamente com práticas preventivas e precaucionárias que possam evitar o acidente e a doença ocupacional indiscriminadamente para todos os trabalhadores. $O$ interesse primordial é de garantia de ambientes saudáveis e seguros para a prestação do trabalho.

Mais uma justificativa em relacionar o tema do meio ambiente do trabalho em uma perspectiva coletiva pode ser encontrada na noção de que os custos com os acidentes e doenças ocupacionais são assumidos não somente pelo empregador, mas pela sociedade como um todo, através do sistema de seguridade social. Portanto, a sociedade organizada tem todo 0 direito de prevenir o dano ocupacional e garantir a salubridade dos ambientes de trabalho.

Por fim, cumpre resgatar que, historicamente, têm sido afirmados determinados direitos diante de dado momento e conjuntura. Assim foi com o reconhecimento dos direitos individuais (civis e políticos), dos direitos coletivos (econômicos, sociais e culturais) e dos direitos difusos (direito ao meio ambiente).

Aqui cabe registrar que não se estabelece um processo de sucessão de direitos como se existissem gerações que aparecessem, dando lugar a

(13) Com efeito, pode ser observado, no Brasil, a atuação do Ministério Público na propositura da Ação Civil Pública, sem deixar de mencionar a ação sindical, órgãos de classe (OAB, CREA), organizaçōes não-governamentais, entidades da sociedade civil, centrais sindicais e do próprio indivíduo na defesa da salubridade dos ambientes de trabalho.

(14) Francesco D. BUSNELLI \& Umberto BRECCIA. / diritto alla salute, pp. 25-27. 
outras; existe, sim, um processo de acumulação, que pressupõe uma compreensão necessariamente integrada e harmoniosa entre os direitos.

Por conta das demandas e transformações operadas na sociedade, tipos diferenciados de direitos foram paulatinamente sendo reconhecidos, como na garantia de direitos liberais, em que os direitos políticos representam uma limitação da atuação estatal; em seguida, por conta das pressões da massa dos trabalhadores por justiça material, com o reconhecimento dos direitos sociais, que requerem uma atuação positiva do poder público (na prestação de benefícios sociais).

Mais recentemente, reconhecem-se direitos originados pelas relações de consumo, impactos ambientais, avanços tecnológicos e pesquisas genéticas.

Enfim, o processo histórico de reconhecimento dos direitos deve ser entendido como uma dinâmica de interação entre as diversas categorias existentes.

Por isso mesmo, a concepção geracional dos direitos tem sido enfaticamente criticada ${ }^{(15)}$, devendo ser reformulada sob a estrita observância da premissa de que as gerações de direitos não se sucedem, paulatinamente.

Pelo contrário, existe a necessidade da unidade fundamental entre os diversos direitos humanos, que se cumulam progressivamente, pois, e. g., "a realização dos direitos civis e políticos seria impossivel sem o gozo dos direitos econômicos, sociais e culturais". ${ }^{(16)}$ Todos devem ser compreendidos como legítimos direitos do ser humano.

Torna-se oportuna a análise de que o direito a justas e favoráveis condições de trabalho - que abriga o direito a uma decente vida para o trabalhador e seus familiares, condições de trabalho seguras e saudáveis, descanso e lazer etc. - e o direito à saúde - que engloba a melhoria de todos os aspectos do meio ambiente e da higiene industrial, a prevenção e tratamento e controle de doenças ocupacionais - são entendidos como direitos humanos pelo Pacto Internacional dos Direitos Econômicos, Sociais e Culturais (ONU, 1966).

A seguir, enfoca-se a amplitude do direito ao meio ambiente do trabaIho, analisando sua autonomia, conteúdo e princípios conformadores, representando efetivamente uma racionalidade diferenciada na proteção da saúde dos trabalhadores dentro de uma perspectiva preventiva.

(15) Cf. Antônio Augusto CANÇADO TRINDADE. Tratado de direito internacional dos direitos humanos, pp. 390-391. O autor refere-se à fantasia nefasta da geração de direitos, histórica e juridicamente infundada, na medida em que alimentou uma visão fragmentada ou atomizada dos direitos humanos, já devidamente desmistificada.

(16) Antônio Augusto CANÇADO TRINDADE. Tratado de direito internacional dos direitos humanos. Porto Alegre: Sergio Antonio Fabris Editor, 1997, pp. 358-359. 


\section{DIREITO AMBIENTAL DO TRABALHO: AUTONOMIA, CONTEÚDO E PRINCÍPIOS FUNDAMENTAIS}

\subsection{Autonomia e conteúdo}

A discussão sobre autonomia das disciplinas jurídicas atende, especialmente, a pressupostos didáticos e metodológicos; por conseqüência, não é oportuno falar em disciplina destacada do sistema científico, na medida em que seria oposto à própria construção da unidade sistemática do direito. Constitui-se, pois, um critério relativo.

Em todo caso, cabe destacar que, tradicionalmente, são exigidas três condições para autonomia de uma disciplina jurídica: domínio suficientemente vasto da matéria, possibilitando um estudo específico e particular; doutrina homogênea dominada por conceitos gerais comuns e distintos dos conceitos gerais informadores de outras disciplinas; e existência de método próprio, que possibilite a adoção de procedimentos especiais para que se conheça o objeto da indagação. Adverte-se que a autonomia não deve se confundir com independência e isolamento(17).

Em que pese a importância e engenhosidade da noção, deve-se compreender simplesmente que existem certas características peculiares de cada ramo da ciência jurídica, que correspondem a determinado objeto e foco de exame, conferindo elemento diferencial em relação a outras disciplinas jurídicas.

Com efeito, observa-se que recentes legislações tutelam de forma sui generis o meio ambiente do trabalho; essa normatividade retoma em parte os interesses de proteção ao meio ambiente combinados aos interesses de garantia de qualidade de vida no trabalho, superando o paradigma da saúde, higiene e segurança ocupacional (como desenvolvido tradicionalmente pela legislação do trabalho); além disso, amplia-se a abordagem acerca do ambiente, superando a posição tradicional (naturalística) da legislação ambiental(18).

Com efeito, essa disciplina em formação surge como resultado da própria complexidade das relações sociais. A emergência da proteção legal ao meio ambiente influencia diretamente paradigmas de tutela no campo laboral. Apresenta-se, hoje, o comando de que o meio ambiente constitui-se direito garantido, e que, por conseqüência, aqueles que trabalham,

(17) Alfredo RocCO. Principii di diritto commerciale, p. 76.

(18) Observa-se que existem doutrinadores com essa leitura tradicional do Direito Ambiental: Jean LAMARQUE. Droit de la protection de la nature et de l'environnement, p. 133. Jehan de MALAFOS. SE. Le droit a la nature,Paris: Montchrestien, 1973. Outros autores apresentam paradigmas que incluem perspectivas diferenciadas e mais amplas: Michel PRIEUR. Droit de L'environnement, com capítulo sobre meio ambiente do trabalho; Michel DESPAX. Droit de l'environnement, com abordagem sobre aspectos do ambiente urbano e estabelecimentos industriais. 
indiscutivelmente, têm direito ao meio ambiente de trabalho saudável e equilibrado.

Cabe entender aqui que hoje ainda é realmente prematuro afirmar a plena autonomia do Direito Ambiental do Trabalho, sobretudo porque a tutela ao meio ambiente do trabalho continua a ser estabelecida em face de a relação de trabalho e a legislação sobre a matéria serem ainda fragmentadas.

Contudo, é importante deixar registrado que a elaboração dessa proteção sofre profunda influência do paradigma emergente que supera a forma tradicional de tutela à higiene e segurança dos trabalhadores. Mais do que isso, seus princípios inspiradores, inobstante muitos deles não serem exclusivos, parecem tomar uma dimensão específica e peculiarizante. Notase, ainda, que essa disciplina pode examinar, de forma mais acurada, as implicações jurídicas da proteção ao meio ambiente do trabalho.

\subsection{Princípios fundamentais}

Após o exame da autonomia e conteúdo do Direito Ambiental do Trabalho, faz-se necessário apresentar que princípios (síntese de seus fundamentos mestres) perfilariam sua estrutura e aplicação. Em uma ampla observação das recentes legislações que tratam do tema do meio ambiente do trabalho, depreende-se uma série de princípios: o princípio da precaução-prevenção, o princípio do desenvolvimento sustentável, o princípio do poluidor-pagador, o princípio da proteção plena ao trabalhador, o princípio da eqüidade e o princípio do in dubio pro ambiente-operario.

Os princípios alicerçam as bases dessa disciplina protetiva aos trabalhadores em seu meio ambiente do trabalho. Percebe-se que, por exemplo, o princípio da prevenção-precaução ocupa espaço importante na medida em que há que se atuar preventivamente e com necessária precaução, rompendo com o paradigma da compensação pecuniária pelo trabalho em condições insalubres.

O princípio do desenvolvimento sustentável caracteriza-se como de importância indiscutível, principalmente em face do desenvolvimento da atjvidade econômica e produtiva, por um lado, e da sustentabilidade (salubridade) dos ambientes de trabalho, por outro.

O desenvolvimento econômico não pode ser dissociado da necessidade de proteção dos ambientes de trabalho. Por mais que os processos de trabalho possam ser aprimorados, o trabalhador deve ter 0 direito de exercer sua atividade em um meio ambiente de trabalho que lhe possibilite o bem-estar e vida com qualidade. 
Quanto ao princípio do poluidor-pagador, ele pode ser consubstanciado na obrigação de o empregador-poluidor reparar os danos causados ao ambiente e aos trabalhadores. Daí, aquele que polui assume a responsabilidade civil, administrativa e criminal do ato. Não se trata de estabelecer a lógica de pagar para poluir, pelo contrário, objetiva-se que possíveis danos sejam evitados, através de medidas preventivas. No entanto, ocorrendo infortúnio no local de trabalho, defende-se a aplicação do princípio da responsabilidade objetiva (responsabilidade sem culpa), havendo que ser apurada, simplesmente, a existência da relação causal (nexo de causalidade) entre o dano e a ação/omissão do poluidor.

O princípio da proteção plena ao trabalhador assenta-se na noção de que qualquer que seja o regime de trabalho, como empregos formais ou contratos atípicos de trabalho, o empreendedor (ou tomador do serviço) tem responsabilidade direta e imediata de implementar medidas preventivas e medidas protetivas de matriz coletiva, para salvaguardar a salubridade dos ambientes de trabalho.

Por conseguinte, apesar de se reconhecer o caráter essencialmente coercitivo e assimétrico das relações de trabalho, com existência de processos diferenciados de prestação (terceirização, quarterização, contratos temporários e transitórios), os trabalhadores devem ter proteção plena de sua saúde, independentemente da forma que tome o referido contrato.

Nesse particular, qualquer que seja a forma contratual, o empregador deve ser responsável pela saúde dos seus trabalhadores, quer exerçam atividade na unidade produtiva ou mesmo no ambiente residencial.

O princípio da eqüidade fundamenta-se na igualdade de proteção nos ambientes de trabalho. Conseqüentemente, se todos os trabalhadores têm o direito ao meio ambiente do trabalho saudável, a meta deve ser que a eliminação e a minimização do risco deva ser estendida a todo e qualquer tipo de trabalho. Não pode ser admitido que a distribuição do risco seja desproporcional. Então, determinados contingentes de trabalhadores não podem ser atingidos mais do que outros na aplicação da política de tutela da salubridade no trabalho.

Por exemplo, pesquisa realizada nos Estados Unidos revelou que a distribuição do risco ocupacional é diferenciada entre determinados grupos raciais. Com efeito, negros e hispânicos, com limitada formação educacional, sofrem desproporcionalmente os efeitos do trabalho em condições perigosas e insalubres. Outro estudo, restrito ao Estado da Califórnia, demonstra que trabalhadores caucasianos são menos afetados com 0 risco ocupacional do que os latinos, que sofrem o dobro de exposição a agentes agressivos. 
O princípio do in dubio pro ambiente-operario consubstancia-se na máxima que, havendo dúvida, se deve proteger o meio ambiente do trabaIho, o que, por outras palavras, significa proteger a saúde dos trabalhadores, inclusive, por precaução.

Por isso, não havendo certeza sobre o grau de periculosidade e/ou salubridade de um ambiente de trabalho, renovação de licença ou autorização para funcionamento da atividade deve ser suspensa pelo órgão licenciador/autorizador. Da mesma forma, indícios de poluição e contaminação em ambientes de trabalho devem ensejar imediata reação da fiscalização do trabalho, independentemente de certeza científica absoluta sobre o incidente.

Nesse particular, trabalhadores que apresentem qualquer variação orgânica por conta das atividades do meio ambiente do trabalho devem ser automaticamente afastados para tratamento e observação médica, independente de parecer conclusivo sobre o assunto. Por sua vez, o meio ambiente do trabalho deve ser criteriosamente vistoriado e monitorado para procura das causas existentes.

Enfim, havendo qualquer alteração das condições do meio ambiente do trabalho, o empregador e as autoridades devem tomar todas as medidas para que não ocorram danos à saúde dos trabalhadores. Em suma, mesmo sem plena certeza da situação insalubre e/ou perigosa, pelo princípio indicado, ações devem ser tomadas para garantir a salubridade dos ambientes de trabalho.

\section{CONSIDERAÇÕES FINAIS}

O tema da proteção jurídica ao meio ambiente do trabalho ocupa lugar crescente na legislação, doutrina e na jurisprudência. A conformação do Direito Ambiental do Trabalho representa um novo paradigma de proteção à saúde do trabalhador. Enfim, percebe-se um cenário de afirmação de qualidade de vida no trabalho e de construção do ambiente do trabalho como locus privilegiado de garantia dos direitos humanos contemporâneos.

\section{BIBLIOGRAFIA}

ALIBRANDI, Giuseppe. Infortuni sul lavoro e malattie professionali. Decima ed. Milano: Dott. A. Giuffré, 1994.

ALPA, Guido \& BESSONE, Mario. Elementi di diritto civile. Milano: Giuffrè, 1990. 
BONCIANI, Mário (org.). Saúde, ambiente e contrato coletivo de trabalho. São Paulo: LTr, 1996.

BUSNELLI, Francesco. D. \& BRECCIA, Umberto. II diritto alla salute.

CAMPILONGO, Celso Fernandes. "O trabalhador e o direito à saúde". In: Direito, Cidadania e Justiça (Coord. Beatriz Di Giorgi, Celso. F. Campilongo \& Flávia Piovesan). São Paulo: Revista dos Tribunais, 1995, pp. 125-140.

CAMPOS, José Luiz Dias. O ministério público e o meio ambiente do trabalho. CAPELLETTI, Mauro. Judicial review in the contemporary world. Indianápolis: Kansas City: New York: The Bobbs-Merrill, 1971.

- "Appunti sulla tutela giurisdizionale di interessi collettivi o diffusi". In: Le azioni a tutela di interessi collettivi. Padova: Cedam, 1976, pp. 190-221.

civil". Revista de Processo, São Paulo, 2 (5): 128-59, 1977.

DENTI, Vittorio. "Relazione introduttiva". In: Le azioni a tutela di interessi collettivi. Padova: Cedam, 1976, pp. 3-22.

DESPAX, Michel. Le droit du travail. $4^{3}$ ed. Paris: Presses Universitaires de France, 1977.

. Droit de l'environnement. Paris: Litec, 1980.

FERREIRA, Daniela Câmara \& FIGUEIREDO, Guilherme José Purvin de. Direito constitucional ao meio ambiente do trabalho seguro e saudável. São Paulo: Max Limonad, 1998.

FIGUEIREDO, Guilherme José Purvim de. Direito ambiental e a saúde dos trabalhadores. São Paulo: LTr, 2000.

FIORILLO, Celso A. P. \& RODRIGUES, Marcelo Abelha. Manual de direito ambiental e legislação aplicável. São Paulo: Max Limonad, 1997.

FIORILLO, Celso A. P. Os sindicatos e a defesa dos interesses difusos no Direito do Processo Civil brasileiro. São Paulo: Revista dos Tribunais, 1995.

HYDÉN, Håkan. Working environment. In: The Nordic labour relations model: labour law and trade unions in the Nordic countries, today and tomorrow. (Org. Niklas Bruun et a). Aldershot: Brookfield: Dartmouth, 1992.

MACHADO, Paulo Affonso Leme. Direito ambiental brasileiro.

MALAFOSSE, Jehan de. Le droit a la nature. Paris: Montchrestien, 1973.

MARTINS FILHO, Ives Gandra. A defesa dos interesses coletivos pelo Ministério Público.

MELO, Raimundo Simão. Segurança e meio ambiente do trabalho: uma questão de saúde pública. 
NERY JUNIOR, Nelson \& NERY, Rosa Maria B. B. Andrade. Código de processo civil comentado e legislação extravagante em vigor. $2^{\mathrm{a}}$ ed. rev. e amp. São Paulo: Revista dos Tribunais, 1996.

NERY JUNIOR, Nelson. "O processo do trabalho e os direitos individuais homogêneos: um estudo sobre a ação civil pública trabalhista". Revista $L T r$, São Paulo, vol. 64, n. 2, fev./2000.

OIT. Introducción a las condiciones y el medio ambiente de trabajo.

PRIEUR, Michel. Droit de l'environnement. $3^{\text {a }}$ ed. Paris: Dalloz, 1996.

RÈMOND-GOUILLOUD, Martine. Du droit de détruire: essai sur le droit de l'environnement. Paris: Press Universitaires de France, 1989.

ROCCO, Alfredo. Principii di diritto commerciale (parte generale). Torino: Editrice, 1928.

ROCHA, Julio Cesar de Sá da. "Meio ambiente do trabalho". Revista TrabaIho \& Doutrina. São Paulo: Saraiva, 11: 104-112, dez. 1996.

. Direito ambiental e meio ambiente do trabalho: dano, prevenção e proteção jurídica. São Paulo: LTr, 1997.

. "Direito ambiental e meio ambiente do trabalho: considerações sobre o ambiente de trabalho rural e a questão dos agrotóxicos". In: $O$ novo em direito ambiental (Org. Marcelo D. Varella \& Roxana C. B. Borges). Belo Horizonte: Del Rey, 1998.

. Direito da saúde: direito sanitário na perspectiva dos interesses difusos e coletivos. São Paulo: LTr, 1999.

SADY, João José. Direito do meio ambiente de trabalho. São Paulo: LTr, 2000.

SANTOS, Boaventura de Sousa. A crítica da razão indolente: contra o desperdício da experiência. São Paulo: Cortez, 2000.

Pela mão de Alice: o social e o político na pós-modernidade. $3^{\text {a }}$ ed. São Paulo: Cortez, 1995.

USSIER, Jorge Luiz. A defesa do meio ambiente do trabalho e da saúde do trabalhador pelo Ministério Público Estadual.

VALENTIM, João Hilário. Direito do trabalho e meio ambiente. 